Genetic forum

\title{
Focus group discussions on secondary variants and next-generation sequencing technologies
}

\author{
Q3 Gabrielle M. Christenhusz ${ }^{\mathrm{a}, *}$, Koenraad Devriendt ${ }^{\mathrm{b}}$, Hilde Van Esch ${ }^{\mathrm{b}}$, Kris Dierickx ${ }^{\mathrm{a}}$ \\ ${ }^{a}$ Centre for Biomedical Ethics and Law, KU Leuven, Leuven, Belgium \\ ${ }^{\mathrm{b}}$ Centre for Human Genetics, KU Leuven, Leuven, Belgium
}

\section{A R T I C L E I N F O}

\section{Article history:}

Received 11 July 2014

Accepted 20 January 2015

Available online $\mathrm{xxx}$

\section{Keywords:}

Disclosure

Ethics

Incidental findings

Whole genome sequencing

Children

Clinical genetics

\begin{abstract}
A B S T R A C T
The clinical application of new genetic technologies will be and already is of great benefit to children with unexplained developmental disabilities or congenital anomalies. In most cases, it will be their parents who, together with medical professionals, make decisions about what should be disclosed and how the information will be used. We conducted eight exploratory focus group discussions with stakeholders to provide a broad sketch of concerns and ideas around the communication of results from next-generation sequencing technologies involving children. Stakeholders included those with (grand-) children of various ages and those without children; those involved professionally with genetics and those who were not; and a range of ages. Participants were asked to focus on which secondary variants they would and would not want disclosed about their (hypothetical) children or themselves. While the literature often concentrates on the medical and scientific characteristics of secondary variants, focus group participants were also interested in factors involving the parent-child relationship and the broader context. This resulted in more flexibility surrounding the types of secondary variants disclosed to parents than much of the literature currently supports. In addition, participants would on occasion use the same factors to argue opposing positions. The "Family Illness Paradigms model" can help explain this seeming contradiction. This model emphasises the importance of how the family reacts to personal and family experiences of disease and loss, more than the fact of having these experiences.
\end{abstract}

(C) 2015 Published by Elsevier Masson SAS.

\section{Introduction}

Thanks to rapidly falling costs, the widespread clinical implementation of whole genome and exome sequencing (WGS and WES, respectively) is imminent [Hayden, 2014]. Some are already using WGS and WES in clinical diagnosis [Choi et al., 2009; Lupski et al., 2010; Worthey et al., 2011]. However, as has often been noted, reports of falling sequencing costs regularly lose sight of invariably high analysis and follow-up costs [Mardis, 2010].

One of the potential causes of high analysis and follow-up costs is the phenomenon of so-called secondary variants or incidental findings. Secondary variants introduce costs at various levels: longer pre-test counselling and informed consent discussions; confirmation of analytical and clinical validity and clinical utility; potential post-test discussions with colleagues, Institutional Review Boards or their equivalents, and patients or research

* Corresponding author. Centre for Biomedical Ethics and Law, Kapucijnenvoer 35, 3000 Leuven, Belgium. Tel: +32 163733 68; fax: +32 16336952 .

E-mail address: gabrielle.christenhusz@med.kuleuven.be (G.M. Christenhusz). participants; plus follow-up costs in primary healthcare. A key step in the development of standard discussion protocols, informed consent procedures, and panels or filters is the investigation of which secondary variants various stakeholders deem worthy of identifying and disclosing and on what basis.

As in a previous study [Christenhusz et al., 2014], we focus here on the particular issue of the disclosure of secondary variants to parents. A qualitative research method was chosen. This allows the emergence of new themes that are relevant to the research participants, a vital step when investigating a new topic. The question of disclosure to parents was focussed on, as it is children with heritable diseases who will be and already are a key beneficiary of the clinical application of new genetic technologies [Boycott et al., 2014]. In most cases, it will be these children's parents who, together with medical professionals, make decisions about what should be disclosed and how the information will be used. Only one official guideline has been published to date on the issue of secondary variants arising from genetic testing, that of the American College of Medical Genetics and Genomics (ACMG) in April 2013 (with revisions published in a press release 
Table 1

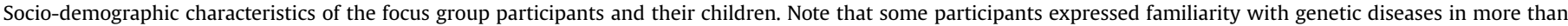
category (family history, studies, or work), so that the numbers in the final column exceed the number of participants.

\begin{tabular}{|c|c|c|c|c|c|c|}
\hline \multirow[t]{2}{*}{ Focus group } & \multirow[t]{2}{*}{$\begin{array}{l}\text { Reason for recruiting this } \\
\text { particular group }\end{array}$} & \multirow{2}{*}{$\begin{array}{l}\text { Recruitment strategy } \\
\begin{array}{l}\text { Number of contact people and } \\
\text { group composition }\end{array}\end{array}$} & \multirow{2}{*}{$\begin{array}{l}\text { Number and } \\
\text { gender of } \\
\text { participants }\end{array}$} & \multirow{2}{*}{$\begin{array}{l}\text { Age } \\
\text { range } \\
\text { Nearest } \\
5 \text { years }\end{array}$} & \multirow{2}{*}{$\begin{array}{l}\text { Children per participant } \\
\text { Median number and age range }\end{array}$} & \multirow{2}{*}{$\begin{array}{l}\text { Familiarity with } \\
\text { genetic diseases } \\
\text { Number through } \\
\text { family history, } \\
\text { studies, or work }\end{array}$} \\
\hline & & & & & & \\
\hline $\begin{array}{l}\text { Parents of young } \\
\text { children }\end{array}$ & $\begin{array}{l}\text { Parents with children of a } \\
\text { certain age; not involved with } \\
\text { genetics professionally }\end{array}$ & $\begin{array}{l}2 \text { contact people delegated; } 2 \\
\text { acquaintance groups }\end{array}$ & $\begin{array}{l}4 \text { women, } \\
2 \text { men }\end{array}$ & $26-45$ & $\begin{array}{l}3 \text { children (under } 5 \text { years of age, } \\
\text { primary school age) }\end{array}$ & $\begin{array}{l}2 \text { family history; } \\
3 \text { through studies; } \\
2 \text { through work; } \\
2 \text { no familiarity }\end{array}$ \\
\hline $\begin{array}{l}\text { Parents of } \\
\text { teenagers and } \\
\text { young adults }\end{array}$ & $\begin{array}{l}\text { Parents with children of a } \\
\text { certain age; not involved with } \\
\text { genetics professionally }\end{array}$ & $\begin{array}{l}2 \text { contact people delegated; } 2 \\
\text { acquaintance groups }+1 \\
\text { stranger }\end{array}$ & $\begin{array}{l}3 \text { women, } \\
3 \text { men }\end{array}$ & $36-55$ & $\begin{array}{l}2-3 \text { children (teenagers, over } \\
18 \text { years of age still at home and } \\
\text { left home) }\end{array}$ & $\begin{array}{l}5 \text { family history; } \\
1 \text { through studies; } \\
1 \text { through work; } \\
1 \text { no familiarity }\end{array}$ \\
\hline $\begin{array}{l}\text { Immigrant parents } \\
\text { (5 Asian, } 1 \\
\text { Middle Eastern, } \\
1 \text { East European) }\end{array}$ & $\begin{array}{l}\text { Parents with a non-Belgian } \\
\text { ethnic background; not } \\
\text { involved with genetics } \\
\text { professionally }\end{array}$ & $\begin{array}{l}\text { Integration office of the } \\
\text { province of Flemish-Brabant; } \\
\text { strangers }+1 \text { married couple }\end{array}$ & $\begin{array}{l}4 \text { women, } \\
3 \text { men }\end{array}$ & $26-45$ & $\begin{array}{l}2 \text { children (under } 5 \text { years of age, } \\
\text { primary school age, teenager) }\end{array}$ & $\begin{array}{l}4 \text { family history; } \\
1 \text { through studies; } \\
3 \text { no familiarity }\end{array}$ \\
\hline $\begin{array}{l}\text { Clinical genetics } \\
\text { centre staff }\end{array}$ & $\begin{array}{l}\text { Parents and involved with } \\
\text { genetics professionally }\end{array}$ & 1 staff member delegated & $\begin{array}{l}4 \text { women, } \\
1 \text { man }\end{array}$ & $36-55$ & 2 children (all ages) & $\begin{array}{l}1 \text { family history; } \\
\text { all through studies; } \\
\text { all through work }\end{array}$ \\
\hline Bio-informaticians & $\begin{array}{l}\text { Involved with genetics } \\
\text { professionally }\end{array}$ & 1 staff member delegated & 7 men & $26-55$ & $\begin{array}{l}4 \text { participants with no children; } \\
3 \text { participants with a mean of } 2 \\
\text { children (all ages) }\end{array}$ & $\begin{array}{l}4 \text { family history; } \\
6 \text { through studies; } \\
6 \text { through work }\end{array}$ \\
\hline $\begin{array}{l}\text { Biological sciences } \\
\text { master students }\end{array}$ & $\begin{array}{l}\text { Not parents; younger than } \\
\text { other groups; familiar with } \\
\text { medicine and genetics through } \\
\text { studies }\end{array}$ & 3 masters classes approached & $\begin{array}{l}4 \text { women, } \\
2 \text { men }\end{array}$ & $18-25$ & 0 children & $\begin{array}{l}3 \text { family history; } \\
6 \text { through studies; } \\
4 \text { through work }\end{array}$ \\
\hline $\begin{array}{l}\text { Genetics PhD } \\
\text { students }\end{array}$ & $\begin{array}{l}\text { Not parents; involved with } \\
\text { genetics professionally }\end{array}$ & Fellow PhD students & $\begin{array}{l}4 \text { women, } \\
3 \text { men }\end{array}$ & $18-45$ & 0 children & $\begin{array}{l}3 \text { family history; } \\
6 \text { through studies; } \\
6 \text { through work; } \\
1 \text { no familiarity }\end{array}$ \\
\hline Grandparents & $\begin{array}{l}\text { Asked to focus on their } \\
\text { grandchildren; older than other } \\
\text { groups; not involved with } \\
\text { genetics professionally }\end{array}$ & $\begin{array}{l}2 \text { contact people delegated; } 2 \\
\text { sets of siblings and } 2 \text { strangers }\end{array}$ & $\begin{array}{l}4 \text { women, } \\
2 \text { men }\end{array}$ & $46-75$ & $\begin{array}{l}4 \text { grandchildren (under } 5 \text { years } \\
\text { of age, primary school age), } 2 \\
\text { adult children }\end{array}$ & $\begin{array}{l}2 \text { family history; } \\
1 \text { through studies; } \\
3 \text { no familiarity }\end{array}$ \\
\hline
\end{tabular}

on 1 April 2014) [Green et al., 2013]. Other guidelines are currently being drafted. The ACMG guideline recommends that a list of secondary variants (confirmed mutations associated with serious conditions judged to have clinical utility) be checked every time WGS or WES is conducted in a clinical setting, regardless of the patient's age. This appears to contradict existing guidelines prohibiting the genetic testing of children for adult-onset conditions [Borry et al., 2009; Clayton et al., 2014]. The ACMG justified the policy change by arguing that secondary variants are qualitatively different to primary genetic test results, because disclosure of secondary variants can provide significant information to the child-patient's family (specifically, the childpatient's parents) that would not be known otherwise [Evans, 2013]. One of the aims of the present study was to investigate whether the time of onset of a genetic condition is considered to be a relevant factor to parents in secondary variant disclosure discussions, and thus indirectly investigate whether participants support previous or emerging guidelines.

In contrast to other published qualitative studies, we did not divide our focus groups according to medical professionals and lay people. Previous research by Lemke et al. suggests that clinical genetics professionals may be more conservative in their disclosure recommendations for parents of patients compared to what they would like disclosed about their own child [Lemke et al., 2013]. In the present study, we wished to concentrate on the respondents as parents (or hypothetical parents), not as medical experts. Furthermore, all focus group participants were instructed to respond as realistically as possible, and the moderator occasionally reminded participants that the researchers were not interested in what the participants thought parents in general should or should not do, but in how the participants thought they themselves would act in a given situation. Responses based on personal experience and what was judged to be personally meaningful were encouraged over hypothetical views [Rabiee, 2004]. In the current study, all responses about secondary variant disclosure were of course unavoidably hypothetical as none of the participants had direct experience with receiving secondary variants regarding themselves or their children. In addition, the two student groups could only respond as hypothetical parents. To offset this, participants were encouraged to respond as personally as possible, and to reflect on and discuss what they would do as (grand-) parents in the context of their specific (grand-) children. The parents were asked what they personally would like to be told; those without children were asked what they thought they would like to be told if they were parents; and the grandparents were asked what they thought their children should be told about their grandchildren.

\section{Methods}

The aim of the focus group discussions was to provide a broad sketch of concerns and ideas around the communication of secondary variants from next-generation sequencing technologies involving children. Ethics committee approval was sought and obtained from the medical ethics committee of the University Hospitals Leuven (study number S54646). Recruitment was conducted through designating one or two contact people per target population. We aimed for between five and eight participants per group [Hydén and Bülow, 2003; Kitzinger, 1995]. A range of stakeholders was recruited (Table 1): participants with (grand-) children of various ages and those without children; participants involved professionally with genetics and those who were not; 
and participants with a range of ages. Purposive sampling was used; this ensures the recruitment of those who have something to say and are willing to talk to each other because they share certain characteristics in common [Hydén and Bülow, 2003; Rabiee, 2004]. Participants received an invitation letter, an information brochure, and a reminder email or phone call before the scheduled focus group discussion, refreshments during the discussion, and a small token of appreciation (a university coffee mug) at the end. Participation in the discussion was understood as implicit consent to the research.

An hour was allotted to each focus group, and a moderator (GC) and observer were always present. A location and time was chosen that best suited the participants. Two of the focus groups were conducted in English (immigrant parents and genetics PhD students) and the remaining six in Dutch. Citations below have been translated into English when necessary. The English version of the discussion guide is reproduced in Online Supplementary Material $\mathrm{S} 1$. A relatively structured format for the discussions was favoured to facilitate the consistency of data collection [Morrison-Beedy et al., 2001]. At the same time, the moderator and observer restricted their interventions, to ensure that it was the participants leading the conversation amongst themselves according to what they perceived to be important [Smithson, 2000]. Participants were assured in writing in an information brochure and orally at the start of a focus group discussion that all results would remain confidential, and that their participation would have no possible effect on their interactions with the university hospital. At the end of the discussion, participants were asked to fill out a socio-demographic form, including the number and ages of their (grand-) children and whether or not they were familiar with genetic diseases (specifically, whether they were familiar with genetic diseases in their family, through their studies, and/or through their work).

Three scenarios were presented to participants (time permitting). The first two scenarios involved a range of secondary variants found in the participant's (grand-) child (or their hypothetical child, where relevant) presenting at a genetics clinic with a suspected genetic condition (Scenario 1), or found in themselves (Scenario 2). The third scenario involved the same secondary variants but as the primary target of genetic testing. As this scenario was only discussed by three groups, and the discussion usually revolved around what the participants wanted to know about themselves rather than their children, results from scenario three were ultimately omitted from the analysis. As in a previous study [Christenhusz et al., 2014], the word "unexpected result" was used with participants. "Unexpected result" is a term that could be easily understood by participants and is easy to translate into Dutch without sounding overly technical, although this is not our preferred term in professional discussions [Christenhusz et al., 2013a]. The "unexpected results" were contrasted with the "expected result," a diagnosis or explanation for the child's suspected genetic condition. Participants were presented with short descriptions of seven (eight in scenario 2) possible "unexpected results," and asked in pairs to arrange the variants in terms of what they definitely did or did not want disclosed, and what they felt ambivalent about. This almost pedagogical method of running the discussion guaranteed a common communicative ground, which was helpful because most of the participants had no direct experience with the topic of secondary variants arising from next-generation sequencing technologies [Hydén and Bülow, 2003]. It also made it easier for participants to focus their comments on each other rather than the moderator, as they sought to explain their choices to each other [Kitzinger, 1995]. Moreover, by giving everyone a chance to first organise their thoughts around something concretely in pairs, those who were slower verbalisers were not disadvantaged. Examples had been chosen based on our two literature reviews and a method for categorising secondary variants developed by Berg et al. [Berg et al., 2011; Christenhusz et al., 2013b, 2013c]. Examples differed in terms of severity, treatability, time of onset, level of risk, carrier status, stigmatisation potential, and health relevance. These factors served as a starting point for the ensuing discussions on why participants had placed the secondary variants where they had.

Transcripts of the discussions were analysed using NVivo 9 software and content and narrative analysis methodologies [Hsieh and Shannon, 2005; Riessman, 2005; Smith, 2000]. While content analysis focuses on specific characteristics of the data, narrative analysis takes a more holistic view, focussing more on context and perspective [Smith, 2000]. These complementary modes of analysis are very well-suited to the methodology of focus group discussions, in which participants develop their opinions together, synergistically [Smithson, 2000]. Codes were developed by the moderator (GC) and subsequently agreed upon with two coauthors (KDV, KD). The analysis focussed on statements made by participants regarding what they would personally expect, desire or decide as a parent. In particular, whenever a participant stated that their personal and professional views conflicted regarding the disclosure of a particular secondary variant, the conflict was noted and only the participant's personal view was included in the analysis.

\section{Results}

\subsection{Study population}

A total of 50 individuals participated in eight exploratory focus groups between October 2012 and May 2013 (Table 1). Twenty seven were parents, six were grandparents, and seventeen had no children. An additional 7\% failed to turn up when expected, although this only occurred with three groups. Groups consisted of an average of six participants, being mixtures of acquaintances (colleagues, friends and/or occasionally family members) and strangers. Given the potentially wide-ranging scope of the topic, this proved to be the ideal number to ensure that all participants had a chance to share all they wanted to say within the one hour time limit. The focus of our gatherings was sufficiently clear that strangers were able to talk easily with each other, and sufficiently novel that acquaintances did not start talking off-topic. Approximately $25 \%$ were non-Belgian, spread across half of the groups (most of course in the group which specifically recruited immigrants). Some expressed no familiarity with genetic diseases either through family history, studies or work; however, this was never more than half of the group (Table 1). A range of ages for participants and their children were represented. Women usually outnumbered men, though never markedly. One group (of bioinformaticians) coincidentally consisted of only men. No differences were noticed between genders, except in discussions on a secondary variant of the father's infertility (implying misattributed paternity).

\subsection{General findings}

After a brief introduction to each scenario, focus group participants were asked in pairs to arrange examples of secondary variants (heart arrhythmia, breast cancer, carrier of cystic fibrosis, increased risk of type 2 diabetes, Huntington's disease, higher percentage of Neanderthal DNA, late-onset Alzheimer's disease, and male infertility) according to those which they definitely wanted to know, those which they definitely did not want to know, 
and those which they did not mind if they knew or not. The arrangement of examples served as a springboard for discussions on what motivated participants in their disclosure preferences. Participants often changed the position of particular examples in the course of a scenario, due to the arguments of others or their own changing arguments. As a result of this changeability, and because we are more interested in participants' arguments and motivations than their mere disclosure preferences, we have not included a figure showing the disclosure preferences of each focus group. In general, more participants were in favour of the disclosure of secondary variants such as heart arrhythmia and breast cancer, than the disclosure of late-onset Alzheimer's disease. No clear pattern of support for or opposition to disclosure could be discerned for the other examples of secondary variants. All groups were split on the disclosure of the father's infertility. Male respondents reacted more personally to this secondary variant example than female respondents did, although some men then argued in favour of disclosure while others argued against it.

On occasion, participants noted that they would respond differently depending on their role. Some said they would like to know more about themselves than about their (hypothetical) children, some less. One PhD student (PhD student 4, male, no children) said he would like to know more if he were a parent than he would be willing to disclose as a doctor. In contrast, one clinical geneticist (clinical geneticist 5, female, two children under 5) said that she would like to know less as a parent than what they had agreed upon as a department that parents should be told. The results that follow deal only with what parents said in their role as parents (or students or grandparents said about parents). The tension in roles will be returned to in the discussion.

At one point in the focus group discussion involving parents of teenagers and young adults, one of the participants (parent of teenagers and young adults 5, male, two children over 13) expressed with a little frustration, "It's just all so arbitrary, it's so, so, unbelievably person-dependent and situation-dependent ... and disease-dependent too, I don't know ..." This is actually a useful and succinct way of dividing the types of arguments that surfaced in discussing the return of secondary variants. Rearranging the three types of factors shows a gradual broadening of focus, from specific characteristics of the secondary variant itself (disease-dependent factors) through the main actors directly affected by disclosure (the parents and their child who is the patient, falling under persondependent factors) to contextual factors broader than the parents and child (situation dependent factors). We present below arguments and motivations arranged according to these three themes related to secondary variants in general (summarised in Table 2); Online Supplementary Table T1 displays those arguments that were more specific to each of the eight secondary variants presented to participants.

\subsection{Factors related to the specific characteristics of the secondary variant}

The actionability of a secondary variant was a major topic of discussion, which included the possibilities of treatment, prevention strategies such as screening or behavioural changes, and prenatal options. The seriousness of the recommended treatment and how easy the condition would be to control once parents knew about it were also raised as factors; that is, conditions that would require more serious or risky treatments or that would be more difficult to control, were more likely to be classified by participants as "do not disclose."

There was almost universal agreement across all groups that life-threatening conditions be disclosed to parents, especially if the information would prove to be life-saving because the condition
Table 2

Disclosure themes raised for discussion, grouped around three types of factors: factors related to the specific characteristics of the secondary variant; factors related to the parents and child-patient; and factors related to the broader context.

\begin{tabular}{cl}
\hline $\begin{array}{c}\text { Specific characteristics } \\
\text { of the secondary } \\
\text { variant }\end{array}$ & Actionability \\
& Life-threatening/life-saving \\
Parents and & Timing \\
child-patient & Rertainty/risk \\
& Rights of parents vs. rights of children \\
& Privileged relationship of parents \\
(Potential) guilt \\
Broader contextual & Identity questions \\
factors & Role of the clinical geneticist or doctor \\
& Wider family \\
& Broader philosophical convictions \\
& (regarding secondary variants as information; \\
& relative importance of genetic information; \\
& concern with genetic advances) \\
\hline
\end{tabular}

once known could be treated or prevented. However, some participants could envision reasons why they may not want to know all life-threatening conditions. One parent of young children (parent of young children 1, male, two children under 5 and one under 13) distinguished between life-threatening conditions in which the predicted progression would be slow and drawn-out (which he did not want to know) and those in which the predicted onset would be sudden (which he did want to know, to have the chance to say goodbye). Two parents of teenagers and young adults expressed doubt about the usefulness of knowing life-threatening conditions, arguing that it is of course impossible to know exactly when the crisis might hit (Online Supplementary Table T1, heart arrhythmia example). One of these mothers (parent of teenagers and young adults 3 , female, three children over 18 ) talked about a similar experience when her daughter had her first epileptic fit and their "world stood still"; no one in the family knew of the risk in advance. As this participant continued to compare the hypothetical example of heart arrhythmia with her personal experience with a daughter with epilepsy, she became increasingly unsure of whether she would want to know such a finding in advance or not. Ultimately, assisted by the input of another participant, this participant concluded that a major reason favouring disclosure would be the availability of effective preventive measures, which was assumed to be the case for heart arrhythmia but not for epilepsy:

But imagine that you had known about it [epilepsy] beforehand, it was still going to happen, probably, wasn't it? (parent of teenagers and young adults 5, male, two children over 13)

Yes, probably, yes (parent of teenagers and young adults 3, female, three children over 18)

Yeah because there's no preventive medication you can take in advance, I assume? (parent of teenagers and young adults 5)

This example illustrates how participants drew on their own experiences to develop their arguments, and how this happened as a process with input from other participants.

The importance of timing was discussed in a range of ways. For example, some discussed the relevance of when the finding would manifest. There were arguments in favour of the disclosure of earlyonset conditions such as heart arrhythmia and against the disclosure of late-onset conditions such as Huntington's disease and lateonset Alzheimer's disease. At the same time, some made a distinction based on when the life of the child would be impacted by the condition, rather than when the child would start to show 
symptoms of the condition. Such participants characterised conditions like breast cancer or Huntington's disease as "early-impact," because even though the child would not develop these conditions during childhood they would be impacted during childhood if their parent got sick and the genetic cause was unknown. Participants who made such a distinction argued that so-called "early-impact" conditions should be disclosed to parents, contrasting these conditions with "late-impact" conditions like (late-onset) Alzheimer's disease which would appear after the children had reached majority and which therefore did not need to be disclosed during childhood. Some participants wondered if the secondary variant could just sit in the medical file until it became relevant or vital. Disclosure only once symptoms started appearing could provide a reassurance of what was happening, and lead to a timely diagnosis. Others cast doubt on the practicality of this suggestion by pointing out that it is difficult to correctly diagnose certain conditions such as Huntington's disease or Alzheimer's disease in the early stages, and so it may be difficult to know when "relevant" is. In addition, it might be difficult to know when the time is ripe to tell the child. Some expressed hope that what is now not actionable may become so in the future; there was then debate about whether the medical file and/or doctors, or parents themselves, were the best keepers of such information on behalf of the child. The importance of being "on time" with treatment and prevention was weighed against the intervening years of worried vigilance. Some argued that they could just wait until symptoms started appearing.

The certainty of the finding was discussed in various ways, and it was sometimes difficult to know what participants precisely meant with this term. Sometimes this referred to the reliability of the genetic test and the certainty of the doctor about the finding. At other times this referred to the predictive value of the finding, and how certain one could be about the time and mode of onset, progression, and clinical manifestation range of the condition. It was not always clear whether participants understood the distinctions between reliability of the test and predictive value of the finding; for example:

.. but if for example ah Alzheimer's disease, if you say that that is only $50-50 \%$, then no thank you, don't tell me. We wouldn't like to know. I don't know with you, is that 50-50 for you? (immigrant parent 7, female, two children under 5 and one child over 13)

yeah (immigrant parent 6 , female, one child under 5)

if they say that the test is only $50 \%$ correct (immigrant parent 7) $\mathrm{mmm}$ (immigrant parent 6)

so $50 \%$ chance that you don't have this problem, would you still like to know? (immigrant parent 7)

no (immigrant parent 6)

This highlights the importance of clarifying what parents and medical professionals mean by words like "correct" and "chance" in genetic consultations. The idea of certainty was also linked to that of risk, as seen in the excerpt above, though there was no consensus as to how high a risk should be to be judged worth reporting, or what doctors should do about large ranges of risk. Some wished to know risks "just in case." Others spoke about the potential meaninglessness of statistics, and the complexity of interpretation brought about by additional environmental and lifestyle factors.

\subsection{Factors related to the parents and child-patient}

Particular ideas about the parents and the child who was the patient often influenced discussions, specifically the relationship between parents and children and their respective roles. One central idea was the responsibility of parents. This was translated in various ways: parents should know about early-onset secondary variants, because at that time of life they are still responsible for their children; parents are responsible to learn about treatable or preventable conditions and then act accordingly; parents are responsible to store late(r)-onset secondary variants on behalf of their child. Regarding the latter, some argued that as long as someone took responsibility to make sure the child received the information when they wanted it, it did not matter if this were someone other than the parent.

Discussions about rights could go in two directions: the rights of parents to know and then make choices, which for some included the choice not to tell the child if the parents thought this best; and the right of the child not to know or not to have their parents know, coupled with the idea that people have more right to know something about themselves than about their children. One grandfather (grandparent 1, male, four grandchildren of various ages and two children) argued passionately that genetic information was the "personal passport" of the child and should be kept private. Some felt that the doctor did not have the right to say they would not disclose. This was related to the sentiment that it was not right for someone else to know something about the child that the parents did not know, whether that be misattributed paternity or any of the other examples.

The privileged relationship of parents to their children was discussed in several ways. Several participants without children from the groups of bio-informaticians and $\mathrm{PhD}$ students suggested that because the parents know their child best, they should stand central in disclosure decisions. One participant explained that it is in the best interests of the child that the parents know and can decide, especially in the context of ambiguous information that may not be immediately relevant:

Yeah I would, I think I'm adult enough and I understand enough about the technology to see, yeah, what it's worth, and then it's up to [us as] parents to decide, to communicate, what we'll do with it. But I do think it's up to us because we completely, we know our children a lot better and we [have] a lot more information than anyone else. So I think for the child that it's, that it's best that all the information be centralised because otherwise ... (bio-informatician 4, male, without children)

However, there was concern in these and other focus groups that knowing might harm the parent-child relationship, by making the parent's role more difficult or by negatively influencing either the parent's or the child's behaviour. One mother of teenagers (parent of teenagers and young adults 2, female, two children over 13) argued that parents have enough choices to make anyway. It was acknowledged that all parents are different, and that disclosure of secondary variants may not be a good idea to parents more prone to worrying or being over-bearing, or those not able to handle the information. Some grandparents and students queried why the parents should be told first.

Two final factors related specifically to parents and children were raised in the focus groups. Discussions about guilt could go in two ways: guilt if the parent could have known and chose not to, and the guilt in knowing that you passed it on to your child (or grandchild). There was concern that guilt might in turn harm the couple's relationship (i.e. the relationship between the parents of the child). Finally, there were concerns amongst parents of teenagers that disclosure of secondary variants to the child or even the young adult (over the age of 18 ) might raise identity questions for them; that is, they might have difficulty incorporating the 
knowledge of the secondary variant into their identity as a person with certain fixed expectations about their present and future health.

\subsection{Factors related to the broader context}

The broader contextual factors raised for discussion can be further divided into three groups: the clinical geneticist or doctor, the wider family, and broader philosophical convictions. Included in the former were discussions on the role of the doctor. Note that "the doctor" was used for various medical professionals without distinction, including clinical geneticists and general practitioners (GPs). As mentioned above, some felt that if someone else, such as the doctor, knew a certain secondary variant, then they as the parent should know too. The doctor was seen as having a responsibility or duty to disclose actionable findings; one grandmother (grandparent 4, female, four grandchildren of various ages and one child) declared: "I would find it criminal if they didn't do that!" Others argued that it would be difficult to devise standard disclosure guidelines that took into account differences between doctors with different levels of expertise and knowledge. The idea that the doctor should just focus on "doing medicine" was used as an argument in four groups (the two student groups, parents of teenagers and young adults, and grandparents) against the specific disclosure of results such as a higher percentage of Neanderthal DNA or misattributed paternity. A similar sentiment was expressed by those who queried the need in general for broad genetic tests, wondering if this would indeed mark an improvement in medical practice.

Related to views on the role of the doctor, the three focus groups not composed of parents (grandparents, biomedical sciences master students, and genetics PhD students) were each asked specifically if they thought parents should ever be forced to accept disclosure of a secondary variant against their will. All three of these groups showed wide-spread support for doctors always disclosing information regarding a potentially life-threatening condition such as heart arrhythmia. Reasons given included the importance of knowing so as to start treatment or screening at an early age, the fact that it was someone else's life (i.e. the child's, not the parents'), and the responsibility or duty of the doctor towards the child. One grandmother (grandparent 6, female, three grandchildren under 13 and two children) suggested that parents who were against the disclosure of all secondary variants would probably not ask for genetic testing in the first place. However, if parents did opt for genetic testing while opposing the disclosure of some or all secondary variants, this grandmother expressed discomfort at the idea of making certain types of disclosure compulsory for parents; she felt that final responsibility lay with the parents, not the doctor. One grandfather (grandparent 1, male, four grandchildren of various ages and two children) responded by proposing that the doctor should be allowed to evaluate the situation and the desirableness or timeliness of disclosure, but that in general the doctor should disclose such information:

But I think in that case, ah then I assume that the doctor, and certainly the GP, is pretty well situated to then look at the situation and the family ah ... he can evaluate it and see what ... what would be best for him to do in that case, and he decides that there must, yeah he makes the decision himself, whether he says it or not (grandparent 1, male, four grandchildren of various ages and two children)

Yes, exactly (grandparent 6, female, three grandchildren under 13 and two children, critical towards compulsory disclosure)

And he has to evaluate it (grandparent 1)
Mmmm yes (grandparent 3, female, four grandchildren under 13 and two children)

Eh? You can come across situations in a family where it's not appropriate ... (grandparent 1 )

In terms of the rest of the family, some described having a family as an incentive to want to know, to then make decisions of benefit to the family; many were open to sharing the information with the wider family. Having a family history of a particular condition, such as type 2 diabetes or Alzheimer's disease, was used to argue both for and against disclosure. A negative family experience with a particular condition made some participants more and some less likely to want to know their risk of that condition. Some members of the focus group of bio-informaticians argued strongly that family history and other health parameters were better predictors of complex, common conditions than genetic makeup. These participants consequently tended towards ambivalence or opposition to disclosure of these types of conditions, and showed more interest in de novo mutations related to less complex conditions. Two other factors related to the wider family which were used to argue against disclosure were a possible negative influence on the family's behaviour if the secondary variant were disclosed, and the concern that the timing may not be right in the family.

Finally, broader philosophical convictions surfaced in all of the focus group discussions, underlying participants' natural preferences for or against disclosure. These convictions formed part of the context influencing disclosure. For instance, there were those who emphasised the informational content of disclosure. They were happy to receive secondary variants to add to all the other pieces of health-related information. They would often also highlight the gap between knowing something and acting on it. Some saw the possibility of tension arising if parents wished to act on a certain piece of information without knowing whether their children might want to know that information. For example, the clinical genetics centre staff members discussed the dilemma of wanting to know and act on a treatable secondary variant such as a BRCA mutation that would be relevant to them as a parent, while still safeguarding their child's future autonomy and right not to know.

A second philosophical standpoint was defended by those who acknowledged that genetic information might in some cases be useful, but whose focus was elsewhere. These participants relativised the importance of genetic information. They did not have to know or measure or weigh everything in general, and were happy to just keep living as they were, healthy and in happy genetic ignorance. Some argued that wanting to know and control everything goes against the philosophy of having children. They argued that not everything can or should be controlled, in contrast to other participants who favoured disclosure of certain variants to give them control over the situation. One master's student (master's student 3, male, no children) passionately argued that all this new genetic knowledge might be a great improvement for science but not for humanity, because knowing all the slight increases and decreases in personal genetic risk will not make us happier.

In contrast to those who brushed off secondary variants as just information were those gravely concerned about the implications of disclosure, particularly if this became standard. Some were worried about the storage and appropriate release of the data, for example release to insurance companies or to the future unsuspecting adult child. One $\mathrm{PhD}$ student ( $\mathrm{PhD}$ student 7, female, no children) spoke of the information as a "time-bomb," so that it was better that no one should know. While some wanted to know even if it would be difficult to hear, others spoke of the burden of knowing. A few were anxious that knowing and worrying about it might hasten the onset of certain conditions. There were also 
concerns amongst some groups not professionally involved in genetics about where to draw the line with genetic information, and about the kind of society that might result from widespread use of next-generation sequencing technologies. As mentioned earlier, some queried the need for genetic sequencing techniques such as WGS in general. One of the parents of teenagers and young adults (parent of teenagers and young adults 2, female, two children over 13) was categorical in her opposition to the disclosure of all secondary variants, favouring a relationship with her child that would be as free as possible from unnecessary worry over the knowledge of what she characterised as "only risks."

\section{Discussion}

The sketch of concerns and ideas around the communication of secondary variants from next-generation sequencing technologies provided by the eight focus group discussions proved much broader than earlier recommendations on the topic [Christenhusz et al., 2013b]. For example, one of the earliest recommendations focused on likely life-threatening and grave conditions that could be avoided or ameliorated [Wolf et al., 2008]. As explained above, we chose the examples of secondary variants used to spark discussion based on these and other factors highlighted in the literature: alongside severity and treatability were the time of onset, level of risk, carrier status, stigmatisation potential, and medical applicability. Our results show both that focus group participants were also interested in other factors such as those involving the parent-child relationship and the broader context (Table 2), and that they would on occasion use the same factors to argue opposing positions. This reaffirms the need for counselling and other forms of dialogue over categories and checklists, to try and uncover which motivations weigh most strongly with parents or patients in specific contexts [Christenhusz et al., 2013c]. Categories and checklists composed by medical professionals may not reflect the values of parents and patients. At the same time, it will be difficult to distil the variety of parental and patient values into categories or checklists that can be universally applied. Moreover, most of our research participants could acknowledge the value of arguments supporting both the disclosure and the nondisclosure of most types of secondary variants, meaning that they would accept the disclosure and nondisclosure of most types of secondary variants if this were justified by arguments. Our results thus support a recommendation for more dialogue between medical professionals and parents or patients before disclosure decisions are made. Many practical questions regarding such dialogues will need to be investigated, such as who should be responsible for leading the discussions, how long they will take, who pays, and how such discussions might be regulated, documented and followed up. The results of empirical ethical research such as the present study can aid in the process of answering such questions.

In terms of minors in particular, the ethical and empirical literature often focus on two points [Christenhusz et al., 2013b, 2013c]. Firstly, the literature advises that more caution should be exercised in the disclosure of incidental findings involving children than involving adults; as a result, usually only the disclosure of life-threatening or grave findings with proven treatability or prevention options is approved. Cases of unlikely net benefit which would usually be left to the discretion of adults are not advised to be disclosed if children are involved [Christenhusz et al., 2013b]. Secondly, in cases of conflict between the rights and best interests of parents and children, the literature usually sides without much hesitation with the children. The results of our focus groups and empirical research of others set these two points against a larger backdrop. Results from focus groups with public stakeholders conducted by Driessnack et al., in contrast to their focus groups with professional stakeholders, echo some of our findings of an openness to the ambiguity of life and the importance of the privileged relationship between parents and children [Driessnack et al., 2013]. This implies a more integrated view of the potential impact of a given finding on the family as a whole than a careful tallying of the net benefits and risks for the child. In 2013, the American College of Genetics and Genomics (ACMG) published recommendations that verifiable, medically actionable findings on their list of secondary variants be sought for and disclosed, regardless of whether the patient is an adult or a child [Green et al., 2013]. They defend this stance by citing a family-wide view of disclosure [Evans, 2013], similar to that displayed by our participants. That is, their argument for disclosure is that any potential clinical benefit to the child's family will also be of indirect immediate benefit to the child. At the same time, our focus group results would not support compulsory disclosure of all secondary variants agreed upon by medical professionals. A more integrated, family-wide view of disclosure suggests the need for a slight re-phrasing of the general recommendation that parents not be given the option to refuse disclosure of serious, treatable, early-onset conditions on behalf of their children [Hens et al., 2011; Wolf et al., 2008]. While only three of our fifty participants called this stance into question, their responses suggest that parents may occasionally have good reason for refusing disclosure at a specific time, although as other participants suggested, such parents would probably not opt for genetic testing at that time anyway.

We observed that the presence of a child, and more specifically the participant's child, in the disclosure equation influenced participants' arguments; as stated above, some participants noted that they would want to know more (and some less) about themselves than their child, and occasionally experts stated that they would be less (or more) likely to want to disclose something if it was a patient than their own child. However, as was also the case when examples of family history were incorporated as arguments, acknowledging that the child focus would influence the decision was not enough to then predict what this decision would be. Family history is seen by some authors, and repeated by some of our participants, as an argument favouring predictive genetic testing of children after appropriate genetic counselling if families specifically request it [Robertson and Savelescu, 2001]. However, other focus group participants used their family history as a reason to not want to know certain secondary variants. The Family Illness Paradigms model may prove helpful here [Rolland, 1987]. The model emphasises the importance of the family's health locus of control (internal or external), their multigenerational experiences with illness and loss, ethnic and cultural background, and assumptions about disease causation on how the family responds to illness. A family's particular illness paradigm could help predict how they might cope as a family with various secondary variants found in their child. This is not to suggest that the illness paradigm should determine what does and does not get disclosed; rather, that it can provide clues as to possible issues that might arise if disclosure or non-disclosure is decided upon. For example, imagine that a BRCA1 mutation were found as a secondary variant. Imagine firstly that a family's experiences with illness have led them to conclude that they have no control over the progression of disease, and that developing a disease is a matter of bad luck or personal guilt. Based on this family illness paradigm, it would be advisable to emphasise during the disclosure of the secondary variant that there are certain prevention techniques available, so that this secondary variant is not automatically received fatalistically by the family. Secondly, imagine another family whose experiences with illness have led them to conclude that with the right 
attitude, medication and lifestyle diseases can be kept under control. Based on this second family illness paradigm, it would be advisable to emphasise during the disclosure of the secondary variant that not all genetic variants associated with an increased risk of breast and ovarian cancer are currently known, and that not all incidences of cancer have a genetic component.

The potential impact of one's family illness paradigm could possibly account for why the results we obtained from interviews with parents whose children had undergone array-CGH testing were more uniform than the wide range of views expressed in focus groups [Christenhusz et al., 2014]. Interview parents formed a more homogeneous group than focus group participants, as they all reported similar stories of long searches for a diagnosis, continuing uncertainty, and loneliness, against a supportive background of (at least one side of the) extended family and clinical genetics staff. In general, participants in both interviews and focus group discussions were conscious of the effect that their unique experiences had on their disclosure preferences, and used these experiences as authoritative arguments. Given the central role of experience in forming preferences and values [Kuczewski, 1996], due weight should be given to patient and family experiences with illness in disclosure discussions.

The relevance of the exact timing and progression of a given genetic condition is often minimised when secondary variants are divided into child-onset and adult-onset conditions, with the corresponding recommendations for disclosure. Some participants affirmed the importance of the time of onset, linking this to protecting the child's right to choose to be tested as an adult and the child's right to privacy. Not respecting these rights can border on instrumentalising the child for the sake of the parents. At the same time, other participants pointed to the importance of the time of impact rather than the time of onset. Illness in the family, whether of the child themselves or their parents, will impact the child while they are growing up. The Family System Genetic Illness model, an adaptation of the Family Illness Paradigms model, emphasises the dimension of time alongside other key genetic disease variables [Rolland and Williams, 2005]. The model highlights the significance of various milestones such as starting a family, work life and retirement when reflecting on the impact of genetic disease. Attention is also paid to the nonsymptomatic time phases of preand post-testing. Because of the variation in the medical and psychosocial demands made on individuals (including children) and the family as a whole across the course of the disease, not all "adultonset diseases" should be treated the same when considering disclosure of secondary variants about children.

We found it an enrichment to bring together genetics professionals (specifically, clinical geneticists and bio-informaticians) in their role as parents. At times they showed a more open attitude to disclosure than has been reported by other professional groups [Brandt et al., 2013; Green et al., 2012; Hayeems et al., 2011; Lemke et al., 2013; Levenseller et al., 2013; Lohn et al., 2013; Townsend et al., 2012]; this might be attributed to the difference between focussing on the individual and aiming at standard guidelines for a large group of people. This begs the question of whether guidelines might benefit not just from the input of a range of stakeholders but also from professionals thinking outside of their usual role.

Possible limitations include the absence of certain stakeholders. In particular, it is unfortunate that our attempts to recruit patient group representatives, paediatric nurses, and parents of ill and disabled children, failed to achieve enough participants. The views of parents of children with learning difficulties or mental disabilities would have been especially enriching, as many of the children who undergo genetic testing fall under this category, and the extent to which these children will be able to make fully independent decisions once they reach adulthood can be uncertain. We suggested in a previous study that the ability of parents to imagine independent grownup children may affect the parents' disclosure preferences, and that this deserves further investigation [Christenhusz et al., 2014]. A complementary study should also include the views of children on their motivations surrounding disclosure. Furthermore, as WGS and WES become more a part of routine clinical genetics practice, retrospective studies should be done with those who have had direct experience with these new technologies, including direct experience with secondary variant disclosure discussions. As was pointed out by some of the genetics professionals who participated, it may have been better if we had emphasised more the risk and therefore uncertain nature of genetic information; in so doing, we may have inadvertently partially contributed to the misconception that genetics is $100 \%$ predictive. It would have been interesting to include psychiatric conditions. All participants live in a single province of Belgium; care should be taken in extrapolating results internationally. Future research could investigate possible impacts on disclosure preferences caused by cultural and religious differences. At the same time, research involving a broader spectrum of stakeholders should refrain from relying too heavily on correlating categories of people with disclosure preferences. As our results suggest, how someone experiences and interprets their life can shed more light on their stated disclosure preferences than a collection of facts and experiences. In line with this finding, further research is needed to explore the impact of the Family Illness Paradigms Model on disclosure preferences and to then translate this into practice.

\section{Conflict of interest statement}

The authors declare no conflict of interest.

\section{Acknowledgements}

$\mathrm{K}$ Devriendt and $\mathrm{H}$ Van Esch are senior clinical investigators of the FWO-Vlaanderen and of the "Interuniversity Attraction Poles" program of the Belgian federal scientific policy office, project P7/43 "BeMGI."

The authors sincerely thank the focus group participants for their time, openness and cooperation. We also wish to thank in particular those who helped with recruitment: Duko Besselsen, Chantal De Keersmaecker, Yves Moreau, Anya Topolski, and Raf Winand. Many thanks also to Simon Godecharle and Kristien Hens for observing three focus groups.

\section{Appendix A. Supplementary data}

Supplementary data related to this article can be found at http:// dx.doi.org/10.1016/j.ejmg.2015.01.007.

\section{References}

Berg JS, Khoury MJ, Evans JP. Deploying whole genome sequencing in clinical practice and public health: meeting the challenge one bin at a time. Genet Med 2011;13:499-504.

Borry P, Evers-Kiebooms G, Cornel M, Clarke A, Dierickx K, Cornel M, et al. Genetic testing in asymptomatic minors: background considerations towards ESHG Recommendations. Eur J Hum Genet 2009;17:711-9.

Boycott KM, Dyment DA, Sawyer SL, Vanstone MR, Beaulieu CL. Identification of genes for childhood heritable diseases. Annu Rev Med 2014;65:19-31.

Brandt DS, Shinkunas L, Hillis SL, Daack-Hirsch SE, Driessnack M, Downing NR, et al. A closer look at the recommended criteria for disclosing genetic results: perspectives of medical genetic specialists, genomic researchers, and institutional review board chairs. J Genet Couns 2013;22:544-53. 
Choi M, Scholl UI, Ji W, Liu T, Tikhonova IR, Zumbo P, et al. Genetic diagnosis by whole exome capture and massively parallel DNA sequencing. Proc Natl Acad Sci U S A 2009;106:19096-101.

Christenhusz GM, Devriendt K, Dierickx K. Secondary variants: in defense of a more fitting term in the incidental findings debate. Eur J Hum Genet 2013;21:1331-4.

Christenhusz GM, Devriendt K, Dierickx K. To tell or not to tell? A systematic review of ethical reflections on incidental findings arising in genetics contexts. Eur J Hum Genet 2013;21:248-55.

Christenhusz GM, Devriendt K, Dierickx K. Disclosing incidental findings in genetics contexts: a review of the empirical ethical research. Eur J Med Genet 2013;56: 529-40.

Christenhusz GM, Devriendt K, Peeters H, Van Esch H, Dierickx K. The communication of secondary variants: interviews with parents whose children have undergone array-CGH testing. Clin Genet 2014;86:207-16.

Clayton EW, McCullough LB, Biesecker LG, Joffe S, Ross LF, Wolf SM, G. For the Clinical Sequencing Exploratory Research Consortium Pediatrics Working. Addressing the ethical challenges in genetic testing and sequencing of children. Am J Bioeth 2014;14:3-9.

Driessnack M, Daack-Hirsch S, Downing N, Hanish A, Shah LL, Alasagheirin M, et al. The disclosure of incidental genomic findings: an "ethically important moment" in pediatric research and practice. J Community Genet 2013;4:435-44.

Evans JP. Return of results to the families of children in genomic sequencing: tallying risks and benefits. Genet Med 2013;15:435-6.

Green RC, Berg JS, Berry GT, Biesecker LG, Dimmock DP, Evans JP, et al. Exploring concordance and discordance for return of incidental findings from clinica sequencing. Genet Med 2012;14:405-10.

Green RC, Berg JS, Grody WW, Kalia SS, Korf BR, Martin CL, et al. ACMG recommendations for reporting of incidental findings in clinical exome and genome sequencing. Genet Med 2013;15:565-74.

02 Hayden EC. Is the $\$ 1,000$ genome for real? Nat News 2014

Hayeems RZ, Miller FA, Li L, Bytautas JP. Not so simple: a quasi-experimental study of how researchers adjudicate genetic research results. Eur J Hum Gene 2011;19:740-7.

Hens K, Nys H, Cassiman J, Dierickx K. The return of individual research findings in paediatric genetic research. J Med Ethics 2011;37:179-83.

Hsieh H-F, Shannon SE. Three approaches to qualitative content analysis. Qua Health Res 2005; 15:1277-88.

Hydén LC, Bülow PH. Who's talking: drawing conclusions from focus groups-some methodological considerations. Int J Soc Res Methodol 2003;6:305-21.

Kitzinger J. Qualitative research. Introducing focus groups. Br Med J 1995;311:299302.
Kuczewski MG. Reconceiving the family. The process of consent in medical decision making. Hastings Cent Rep 1996;26:30-7.

Lemke AA, Bick D, Dimmock D, Simpson P, Veith R. Perspectives of clinical genetics professionals toward genome sequencing and incidental findings: a survey study. Clin Genet 2013;84:230-6.

Levenseller B, Soucier D, Miller V, Harris D, Conway L, Bernhardt B. Stakeholders' opinions on the implementation of pediatric whole exome sequencing: Implications for informed consent. J Genet Couns 2013:1-14.

Lohn Z, Adam S, Birch P, Townsend A, Friedman J. Genetics professionals' perspectives on reporting incidental findings from clinical genome-wide sequencing. Am J Med Genet Part A 2013;161:542-9.

Lupski JR, Reid JG, Gonzaga-Jauregui C, Rio Deiros D, Chen DC, Nazareth L, et al. Whole-genome sequencing in a patient with Charcot-Marie-Tooth neuropathy. N Engl J Med 2010;362:1181-91.

Mardis ER. The $\$ 1,000$ genome, the $\$ 100,000$ analysis? Genome Med 2010;2:84

Morrison-Beedy D, Côté-Arsenault D, Feinstein NF. Maximizing results with focus groups: moderator and analysis issues. Appl Nurs Res 2001;14:48-53.

Rabiee F. Focus-group interview and data analysis. Proc Nutr Soc 2004;63:655-60.

Riessman CK. Narrative analysis. In: Narrative, Memory and Everyday Life. Huddersfield: University of Huddersfield; 2005. pp. 1-7.

Robertson S, Savelescu J. Is there a case in favour of predictive genetic testing in young children? Bioethics 2001;15:26-49.

Rolland JS. Family illness paradigms: evolution and significance. Fam Syst Med 1987;5:482-502.

Rolland JS, Williams JK. Toward a biopsychosocial model for 21st-century genetics. Fam Process 2005;44:3-24.

Smith CP. Content analysis and narrative analysis. In: Reis HT, Judd CM, editors. Handbook of Research Methods in Social and Personality Psychology. Cambridge: Cambridge University Press; 2000. pp. 313-35

Smithson J. Using and analysing focus groups: limitations and possibilities. Int J Soc Res Methodol 2000;3:103-19.

Townsend A, Adam S, Birch PH, Lohn Z, Rousseau F, Friedman JM. "I want to know what's in Pandora's box": comparing stakeholder perspectives on incidental findings in clinical whole genomic sequencing. Am J Med Genet Part A 2012;158A:2519-25.

Wolf SM, Lawrenz FP, Nelson CA, Kahn JP, Cho MK, Clayton EW, et al. Managing incidental findings in human subjects research: analysis and recommendations. J Law Med Ethics 2008;36:219-48.

Worthey EA, Mayer AN, Syverson GD, Helbling D, Bonacci BB, Decker B, et al. Making a definitive diagnosis: successful clinical application of whole exome sequencing in a child with intractable inflammatory bowel disease. Genet Med $2011 ; 13: 255-62$. 